\title{
Acute fever and delayed leukoencephalopathy following low dose intraventricular methotrexate
}

\author{
W BOOGERD, J J vd SANDE, D MOFFIE \\ From the Neurological Department of the Netherlands Cancer Institute (Antoni van Leeuwenhoekhuis) and the \\ Municipal Hospital Slotervaart, Amsterdam, The Netherlands
}

SUMMARY Nine out of 14 patients treated with intraventricular methotrexate (MTX) for meningeal carcinomatosis from breast carcinoma and surviving more than 4 months developed disseminated necrotising leukoencephalopathy (DNL). All four patients who had received both intraventricular MTX and whole brain radiotherapy developed DNL. Five of the six patients who experienced an acute febrile reaction with mild encephalopathic signs following intraventricular administration of MTX developed DNL after a mean time of 5 months and a low mean dose of $44 \mathrm{mg}$ MTX. DNL was also noted in two patients without a previous febrile reaction or whole brain radiotherapy, following prolonged intraventricular MTX therapy after a mean time of 19.5 months and a mean dose of $147 \mathrm{mg}$ MTX. These findings confirm the hazards of (1) high cumulative doses of intrathecal MTX and (2) combined intrathecal chemotherapy and whole brain radiotherapy. This study also suggests a possible relationship between an early and transient febrile reaction during intraventricular administration of MTX and the development of DNL.

Intrathecal (IT) methotrexate (MTX) is widely used to treat or prevent meningeal leukaemia and lymphoma. ${ }^{12}$ It is also successfully applied in patients with meningeal carcinomatosis, particularly from breast carcinoma. ${ }^{3-5}$ Treatment is usually combined with cranial or craniospinal radiotherapy and occasionally with systemic MTX.

The neurological complications of intrathecal MTX administration can be divided into acute and late effects. The acute effects develop within hours and consist of a transient aseptic meningitis or, rarely, a myelopathy or encephalomyelopathy. ${ }^{6-8}$ The reported frequency of MTX meningitis varies from uncommon to more than $50 \% . .^{9-11}$ The symptoms of headache, vomiting and fever usually last 1 or 2 days. There is nuchal rigidity, usually associated with a modest CSF pleiocytosis and elevated CSF protein. ${ }^{9}$ The cause of this reaction is unknown and a number of factors have been implicated. ${ }^{61112}$ Probably MTX meningitis is caused by the drug itself, as it is usually accompanied by elevated CSF MTX levels. ${ }^{13}$ Active meningeal infiltration by malignant cells may be a predisposing factor. ${ }^{13} 14$ The most important delayed

Address for reprint requests: Dr Boogerd, Department of Neurology, Slotervaartziekenhuis, Louwesweg 6, 1066 EC Amsterdam, The Netherlands

Received 5 January 1988 and in revised form 10 May 1988. Accepted 13 May 1988 toxic effect is disseminated necrotising leukoencephalopathy (DNL). It develops between 3 to 15 months after MTX administration and is clinically characterised by an insiduous onset of personality changes, lethargy and dementia, usually followed by hemiplegia or quadriparesis and coma. ${ }^{915}$

Histological examination reveals areas of demyelination, axonal degeneration, astrocytosis and coagulative necrosis, predominantly in the periventricular white matter with or without vascular changes. ${ }^{1617}$ This appears on CT as periventricular areas of decreased density. This complication almost exclusively occurs when IT MTX is combined with cranial irradiation or systemic MTX and seems to be dosedependant. ${ }^{6917}$ The incidence has been reported to be as much as $45 \%$ after high dose radiotherapy $(>35 \mathrm{~Gy})$ in combination with a larger dose of IT MTX. ${ }^{18}$

Hitherto only two patients have been described with DNL following IT MTX without additional cranial radiation or systemic MTX. ${ }^{19} 20$ The administered total dose of MTX in these patients was $217 \mathrm{mg} / \mathrm{m}^{2}$ and $195 \mathrm{mg} / \mathrm{m}^{2}$ respectively. The approximate risk of DNL due to IT MTX without whole brain radiotherapy or systemic MTX is assumed to be less than $1 \%$, provided that a total dose of at least $50 \mathrm{mg}$ of MTX has been administered. ${ }^{21}$

The present report analyses the occurrence of DNL in patients treated with IT MTX for meningeal car- 
cinomatosis from breast carcinoma. It shows that the risk of DNL after single treatment with IT MTX may be considerable and that DNL may even occur after a total dose of less than $50 \mathrm{mg}$ MTX. The role of possible contributing factors is investigated.

\section{Patients and methods}

Thirty-five patients with meningeal carcinomatosis from breast carcinoma were treated with the intraventricular administration of MTX via an Ommaya reservoir. In every patient the diagnosis was confirmed by the demonstration of malignant cells in the CSF. CT of the brain was performed in all patients before the insertion of the Ommaya reservoir. Intraventricular MTX therapy was only administered if concurrent systemic metastases were expected to be treatable. MTX was administered according to a protocol which has been described elsewhere: $5 \mathrm{mg}$ of preservative-free isotonic MTX was injected whenever CSF MTX levels tended to fall below $10-9 \mathrm{~mol} / \mathrm{ml}$ until the disappearance of tumour cells from the CSF. Thereafter, the interval of MTX administration was gradually increased to a maintenance programme of $5 \mathrm{mg}$ once every 6 weeks. During the first treatment weeks in every patient CSF samples were taken at least twice a week from the Ommaya reservoir for culture, cytology, MTX levels and biochemical analysis.

Oral leukovorin was given after IT MTX if bone marrow suppression occurred. Fourteen of the 35 patients survived longer than 4 months after initiation of IT MTX therapy. These 14 patients were analysed for the occurrence of MTX neurotoxicity (table). The mean age of these patients when the diagnosis meningeal carcinomatosis was made was 53 years (range 39-72 years). In an attempt to detect factors which may contribute to the development of neurotoxic complications the area and the intensity of meningeal involvement were investigated, according to clinical signs, neuroradiological and CSF findings. Four patients received whole brain radiotherapy. Two patients (Nos 1 and 2) with parenchymal metastases received $3900 \mathrm{cGy}$ and $4200 \mathrm{cGy}$ respectively 4 and 17 months prior to IT MTX administration. The other two patients (Nos 3 and 4) received whole brain radiotherapy with respectively $1750 \mathrm{cGy}$ and $3000 \mathrm{cGy}$,
6 weeks after the initiation of IT MTX. Patient 4 was irradiated because of a parenchymal metastasis. Patient 3 received additional craniospinal irradiation after IT MTX had been stopped because of possible MTX toxicity. During IT MTX therapy CSF had become negative for tumour cells, although simultaneously some clinical deterioration was noted. Radiotherapy had to be stopped in this patient at $1750 \mathrm{cGy}$ (in 12 fractions) because of severe bone marrow suppression. The CSF remained free of tumour cells.

Two patients (Nos 6 and 11) received local radiotherapy to the skull base because of osseous metastases with $1150 \mathrm{cGy}$ (in four fractions) and $3000 \mathrm{cGy}$ (in 12 fractions) respectively 3 and 6 months before IT MTX treatment. Patient 11 received additional local radiotherapy to the hypophyseal area (2100 cGy in seven fractions).

The diagnosis DNL was made on the basis of typical clinical signs and CT findings. The clinical picture consisted of lethargy, ataxia, dementia and in some cases hemiparesis. CT showed the characteristic hypodensity of the periventricular white matter. Infectious meningitis or an exacerbation of the meningeal carcinomatosis were excluded. In three patients (Nos 4, 5, 7) the CSF Myelin Basic Protein (MBP) level was measured by a radio immunoassay technique (Dr.Out, Academic Medical Centre, Amsterdam) at the diagnosis of DNL. Postmortem examination was performed on two patients with DNL (patients 1 and 5).

\section{Results}

Acute fever (table)

A febrile reaction in the first weeks of IT MTX therapy occurred in six of the 14 patients. Temperature gradually rose 5 to 14 days (mean 9 days) after initiation of IT MTX treatment, that is, after the second or third intrathecal injection and lasted 6 to 16 days (mean 11 days). In most cases fever was mild with temperatures between $38.5^{\circ}-39^{\circ} \mathrm{C}$ and only occasionally rising to $40^{\circ} \mathrm{C}$. Accompanying symptoms and signs were also mild and consisted of headache, nausea and dizziness and in some cases a slight ataxia.

Table Summary of treatment and its neurotoxic complications in patients with meningeal carcinomatosis from breast carcinoma

\begin{tabular}{|c|c|c|c|c|c|c|}
\hline Patient/Age (yr) & Dose of IT MTX & $\begin{array}{l}\text { Whole } \\
\text { brain irradiated }\end{array}$ & Acute fever & $D N L$ & Onset of $D N L$ & $\begin{array}{l}\text { Survival } \\
\text { time after treatment }\end{array}$ \\
\hline $\begin{array}{r}1 / 48 \\
2 / 43 \\
3 / 60 \\
4 / 59 \\
5 / 39 \\
6 / 72 \\
7 / 55 \\
8 / 51 \\
9 / 63 \\
10 / 53 \\
11 / 42 \\
12 / 45 \\
13 / 59 \\
14 / 48\end{array}$ & $\begin{array}{c}55 \mathrm{mg} \\
25 \mathrm{mg} \\
35 \mathrm{mg} \\
30 \mathrm{mg} \\
85 \mathrm{mg} \\
15 \mathrm{mg} \\
55 \mathrm{mg} \\
164 \mathrm{mg} \\
130 \mathrm{mg} \\
100 \mathrm{mg} \\
35 \mathrm{mg} \\
30 \mathrm{mg} \\
65 \mathrm{mg} \\
75 \mathrm{mg}\end{array}$ & $\begin{array}{l}+ \\
+ \\
+ \\
+ \\
- \\
- \\
- \\
- \\
- \\
- \\
- \\
-\end{array}$ & $\begin{array}{l}- \\
- \\
+ \\
+ \\
+ \\
+ \\
+ \\
- \\
- \\
+ \\
- \\
- \\
-\end{array}$ & $\begin{array}{l}+ \\
+ \\
+ \\
+ \\
+ \\
+ \\
+ \\
+ \\
+ \\
- \\
- \\
- \\
-\end{array}$ & $\begin{array}{r}5 \mathrm{~m} \\
7 \mathrm{~m} \\
8 \mathrm{~m} \\
4 \mathrm{~m} \\
4 \mathrm{~m} \\
7 \mathrm{~m} \\
3 \mathrm{~m} \\
26 \mathrm{~m} \\
13 \mathrm{~m}\end{array}$ & $\begin{array}{l}6 \mathrm{~m} \\
7 \mathrm{~m} \\
9 \mathrm{~m} \\
6 \mathrm{~m} \\
7 \mathrm{~m} \\
23 \mathrm{~m} \\
7 \mathrm{~m}+ \\
41 \mathrm{~m} \\
18 \mathrm{~m} \\
10 \mathrm{~m}+ \\
5 \mathrm{~m} \\
8 \mathrm{~m} \\
6 \mathrm{~m} \\
5 \mathrm{~m}\end{array}$ \\
\hline
\end{tabular}

DNL = Disseminated necrotising leukoencephalopathy. 
Nuchal rigidity did not increase in any of these patients. All cultures were negative. In all patients fever disappeared spontaneously without antibiotic treatment. In four patients (Nos 4, 5, 7, 10) IT MTX was continued throughout the period of fever. Only in one patient (No. 3) was some relation apparent between the administration of MTX and the fever shown by temperature peaks within 24 hours following IT MTX.

No significant difference was seen in the extent, the intensity or the course of the meningeal involvement between patients with and without fever. During the febrile reaction the ventricular CSF cell count and protein concentration remained at the same level or became within normal limits.

CSF MTX concentrations in the toxic range as defined by Bleyer et $a l^{13}$ were measured at one or more occasions during the first 4 weeks of IT MTX treatment in four of the six patients with a febrile reaction, and in three of the eight patients without a febrile reaction (fig 1). Notably, no difference was noted in the CSF MTX levels during and after the

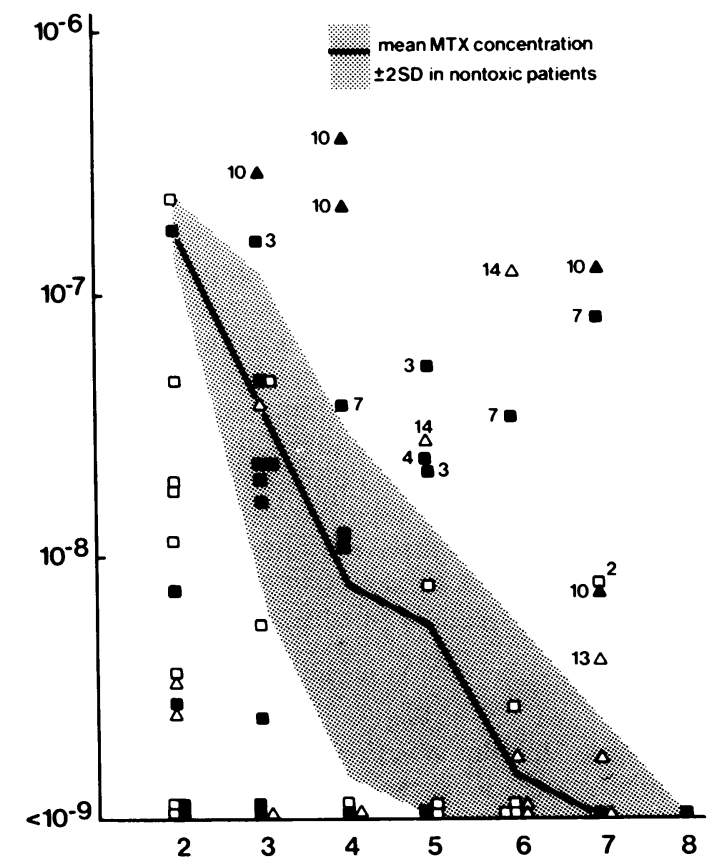

Fig 1 Cerebrospinal fluid (CSF) methotrexate (MTX) concentration in mol/l during the first month of IT MTX treatment. The abscissa represents days after intrathecal $M T X$ injection. The shaded area represents the mean and range of CSF MTX concentrations in patients without acute neurotoxicity according to WA Bleyer et al. ${ }^{13} \square=$ Acute fever,$+ D N L+; \Delta=$ Acute fever,$+ D N L-; \square=$ Acute fever - , DNL +; $\triangle=$ Acute fever -, DNL - ; The numbers designate the patient no. (see table). period of fever in the four patients in whom IT MTX administration was continued. In three patients IT MTX was changed into cytosine arabinoside (ARAC), given in a dose of $40 \mathrm{mg}$ in $2 \mathrm{ml}$ of preservative-free water. In Patient 4 a total dose of $160 \mathrm{mg} \mathrm{ARA-C}$ was given because of simultaneous whole brain radiotherapy for parenchymal metastases. Patient 6 received $40 \mathrm{mg} A R A-C$ because of the febrile reaction during IT MTX. As fever persisted ARA-C was also discontinued. Patient 8 received $80 \mathrm{mg}$ ARA-C because of a clinical and cytological response failure to IT MTX.

\section{Leukoencephalopathy (table)}

Nine of the 14 patients developed DNL 3 to 26 months after the initiation of IT MTX. All four patients who had received whole brain radiotherapy (Nos 1, 2, 3, 4) developed DNL 4 to 8 months (mean 6 months) after the start of IT MTX. The mean total dose of IT MTX in these patients was only $36 \mathrm{mg}$ (range $25-55 \mathrm{mg}$ ). Both patients who received whole brain radiotherapy after IT MTX experienced a febrile reaction in the first weeks of IT treatment. One of these patients (No. 3) received only $1750 \mathrm{cGy}$ (in 12 fractions) after a total dose of $35 \mathrm{mg}$ MTX. MTX was stopped before whole brain radiotherapy. In the other patient (No. 4) MTX was changed into ARA-C during radiotherapy for parenchymal metastases because of the risk of provoking DNL. She eventually received $30 \mathrm{mg}$ MTX and $160 \mathrm{mg}$ ARA-C IT. Two months after radiotherapy she developed signs of DNL. CT showed disappearance of the parenchymal metastasis as well as of the contrast enhancement along the cerebral sulci but on the contrary periventricular hypodensity. Five of the 10 patients without whole brain radiotherapy developed DNL after treatment with IT MTX. The mean total dose of IT MTX in patients with DNL was $90 \mathrm{mg}$ (range $15-164 \mathrm{mg}$ ) versus $61 \mathrm{mg}$ (range $30-100 \mathrm{mg}$ ) in those without DNL. Three of the five patients with DNL had experienced a febrile reaction in the early stage of IT treatment. A mean dose of only $52 \mathrm{mg}$ IT MTX (range 15-85 mg) had been given in these three patients and DNL developed after a short mean time of 5 months (range 3-7 months) (fig 2). In contrast, in the two patients who developed DNL without a previous febrile reaction DNL was diagnosed at 13 and 16 months, respectively after 130 and $164 \mathrm{mg}$ IT MTX. No relation was found between the CSF MTX levels during the first 4 weeks of intensive IT MTX administration and the development of DNL (fig 1). In addition, no relation could be found between the development of DNL and the area or intensity of malignant infiltration. The CSF MBP level (normal $<1 \mathrm{ng} / \mathrm{ml}$ ) was $2.8 \mathrm{ng} / \mathrm{ml}$ in Patient $4,15 \mathrm{ng} / \mathrm{ml}$ in Patient 5 and $5.5 \mathrm{ng} / \mathrm{ml}$ in Patient 7. 

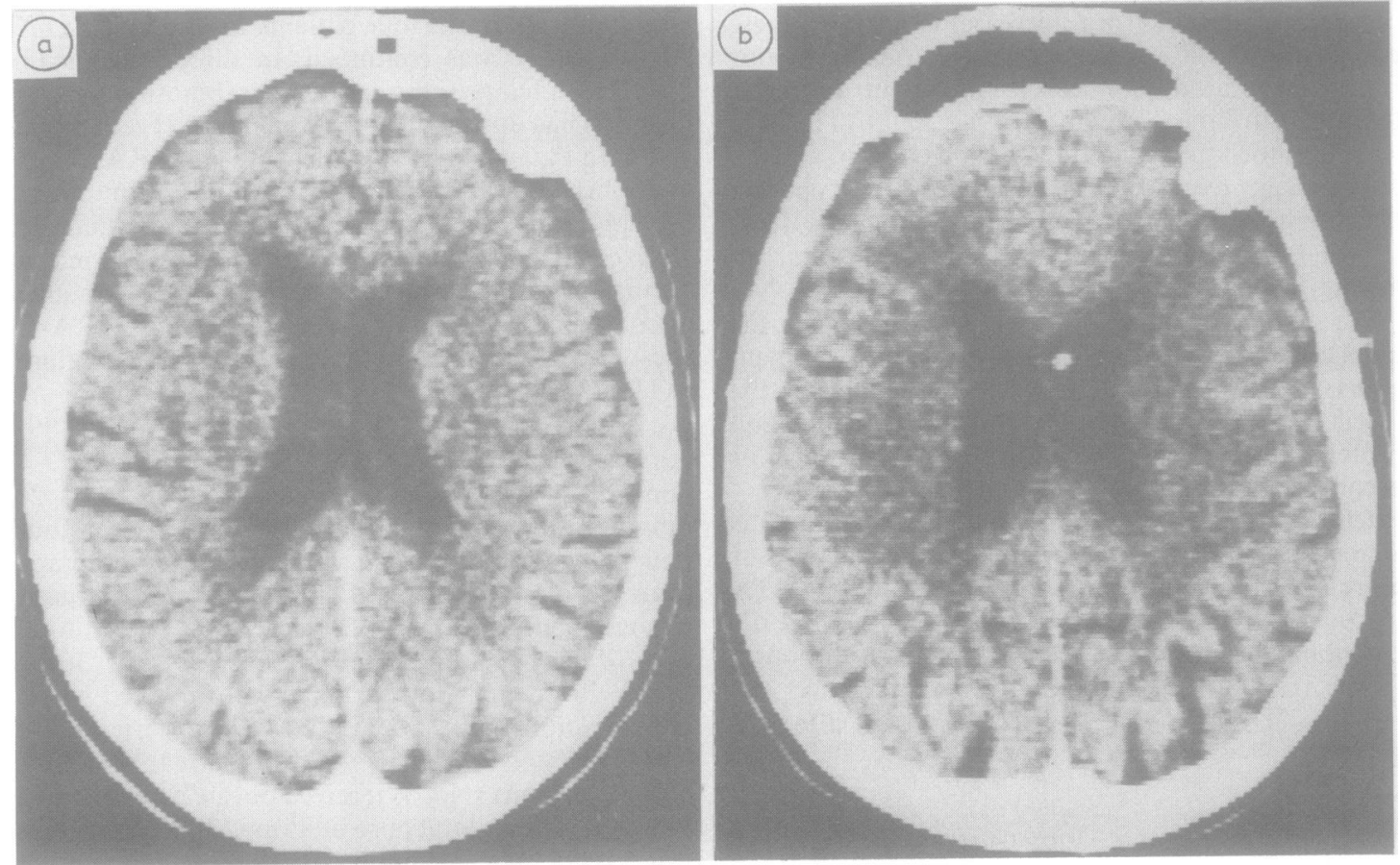

Fig 2 Cranial CT performed in patient no. 6. (A) At the diagnosis of meningeal carcinomatosis before insertion of the Ommaya reservoir. (B) At the clinical diagnosis of DNL 7 months after a total dose of only 15 mg IT MTX, demonstrating hypodensity of the periventricular white matter.

The mean survival time after the initial diagnosis of DNL was 5 months (range 0-16 months). One patient (patient 7) is still alive 4 months after the diagnosis of DNL.

All patients showed a steady deterioration of the DNL. In all patients DNL was the major cause of death or an important contributing factor. However, the mean survival time from the start of IT MTX therapy was 14 months in the patients who developed DNL in contrast with 7 months in those without DNL.

Neuropathological examination showed macroscopically visible foci of necrosis and demyelination in the cerebral periventricular white matter in both patients with DNL examined (fig 3). In Patient 5 these foci were predominantly located in the direct vicinity of the ventricles.

For microscopical examination haematoxylin and eosin, Klüver, PAS and Kossa stains were used. In both patients tumour cells were found in most parts of the subarachnoid space. In Patient 1 a section of the right frontal area showed necrotic lesions, surrounding small areas with relatively intact white matter. In the necrotic lesions macrophages were seen and fields of astrocytosis. The vessels in these areas were thickened by fibrinoid necrosis, with hya- linisation and narrowing of the lumen without real occlusion. The Kossa stain was negative. Microscopical examination of both frontal areas in Patient 5 demonstrated necrotic areas in the white matter with myelin degeneration, cellular remnants, macrophages and some glial reaction and vascular proliferation (fig 4). Hyalinoid and fibrinoid-necrotic changes of blood vessel walls were seen with narrowing of the lumen occasionally with complete occlusion. Amyloid was not observed. The Kossa stain for calcium in the vessel walls was slightly positive.

\section{Discussion}

The acute febrile reaction following intrathecal administration of preservative-free MTX in six patients in the present study differs clearly from MTX meningitis. Fever gradually developed after the second or third dose of MTX without an obvious relation to the moment of injection while it lasted much longer than 1 or 2 days. There were in fact no signs of a meningeal reaction. Nuchal rigidity was absent and CSF did not show a cellular reaction or elevated protein. No significant relation was found with elevated CSF MTX levels, nor with the area or intensity of the malignant meningeal involvement. 


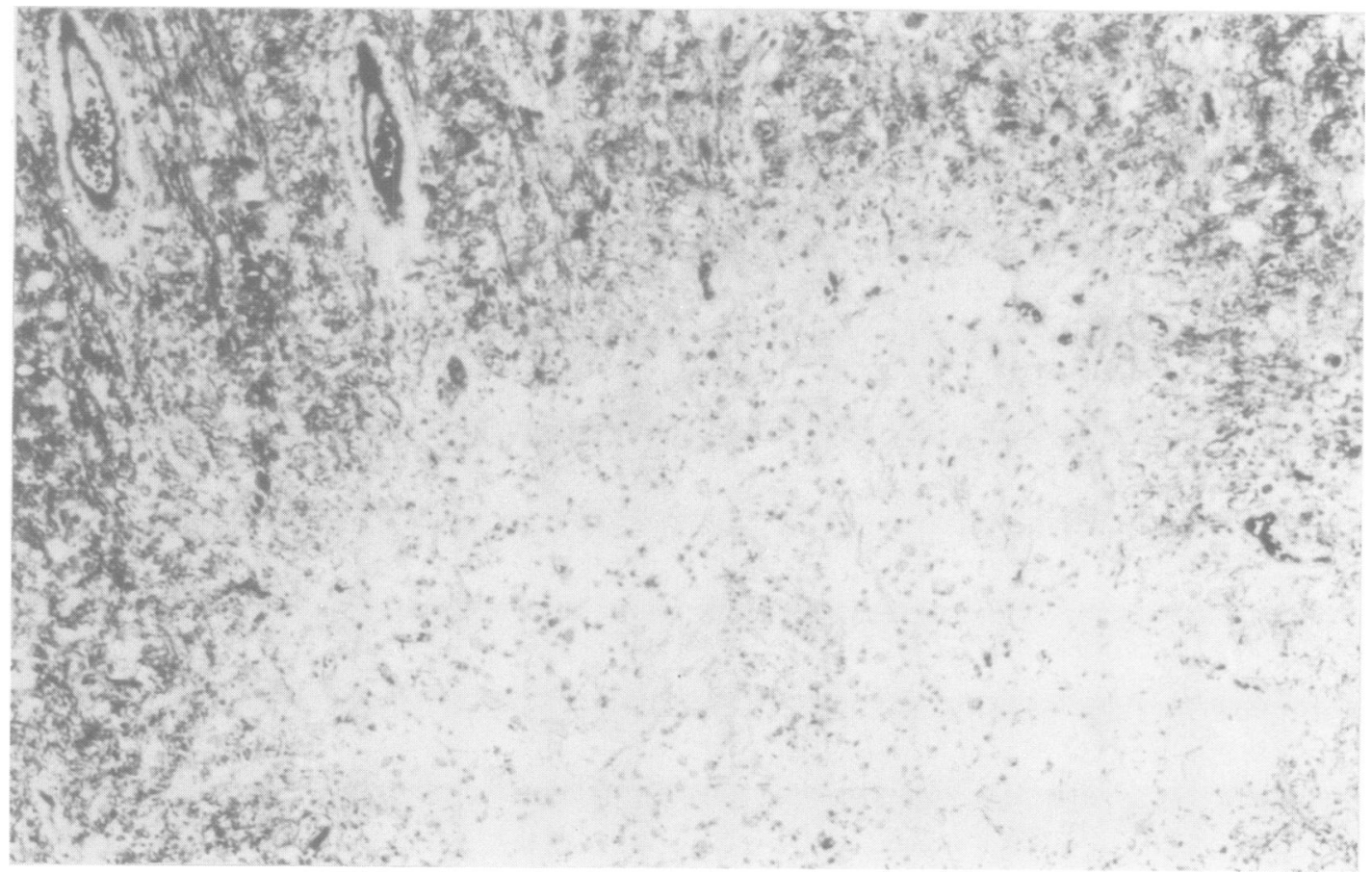

Fig 3 Focal demyelination and cavitation with some macrophages in the periventricular white matter (patient no. 1) (Kluver Stain, × 25).

The dose of MTX per injection in our patients was lower than usually applied.

DNL almost exclusively occurs when IT MTX is combined with whole brain radiotherapy and/or systemic MTX. ${ }^{917}$ The incidence of DNL increases with the cumulative dose of IT MTX ${ }^{17}$ and may be correlated with elevated CSF MTX levels. ${ }^{22}$ The present study shows a clear relation between DNL and (1) whole brain radiotherapy (2) the cumulative dose of MTX and (3) an early febrile reaction. No close relation was found between the occurrence of DNL and ventricular CSF MTX levels. The patients with a febrile reaction developed DNL after a short interval and following a low dose of MTX. Two of these patients had also received whole brain radiotherapy. However, as in both patients IT MTX had been stopped before radiotherapy it is questionable whether radiotherapy has substantially contributed to the development of DNL. ${ }^{14}$ Moreover, the total dose of $1750 \mathrm{cGy}$ in 12 fractions in one of these patients is lower than the estimated minimal neurotoxic dose. 617

Only two cases of DNL following IT MTX without radiotherapy or systemic MTX have been previously described. ${ }^{19} 20$ The cumulative dose of IT MTX of $217 \mathrm{mg} / \mathrm{m}^{219}$ and $195 \mathrm{mg}^{20}$ is in the range of the total dose of MTX (130 mg and $164 \mathrm{mg}$ ) that was given in the two patients in the present study who developed DNL without a previous acute febrile reaction. In other reports concerning DNL following IT MTX the patients had also received high dose intravenous MTX or partial or whole brain irradiation. ${ }^{1622-24}$ This apparent rarity of DNL after IT MTX alone may be partly explained by the fact that in most treatment regimens for neoplastic meningitis IT MTX is combined with other treatment modalities.

Elevation of MBP in CSF is strongly correlated with active demyelination and is likewise always encountered in DNL. ${ }^{2526}$ Accordingly, in the present study CSF MBP was elevated in patients with DNL, including patients treated with IT MTX without whole brain radiotherapy.

The pathogenesis of these various types of MTX toxicity is obscure. In meningeal carcinomatosis CSF flow abnormalities may occur in $70 \%$ of the patients. These abnormalities are often transient during the first weeks of treatment and may consist of ventricular obstruction as well as of a flow delay over the cortical convexities. Importantly, these CSF flow disturbances are not closely associated with abnormalities in CSF cell count or protein nor with CT findings. ${ }^{27}$ So the early transient encephalopathic symptoms in our patients might have been caused by an increased MTX diffusion into the cerebral parenchyma due to 


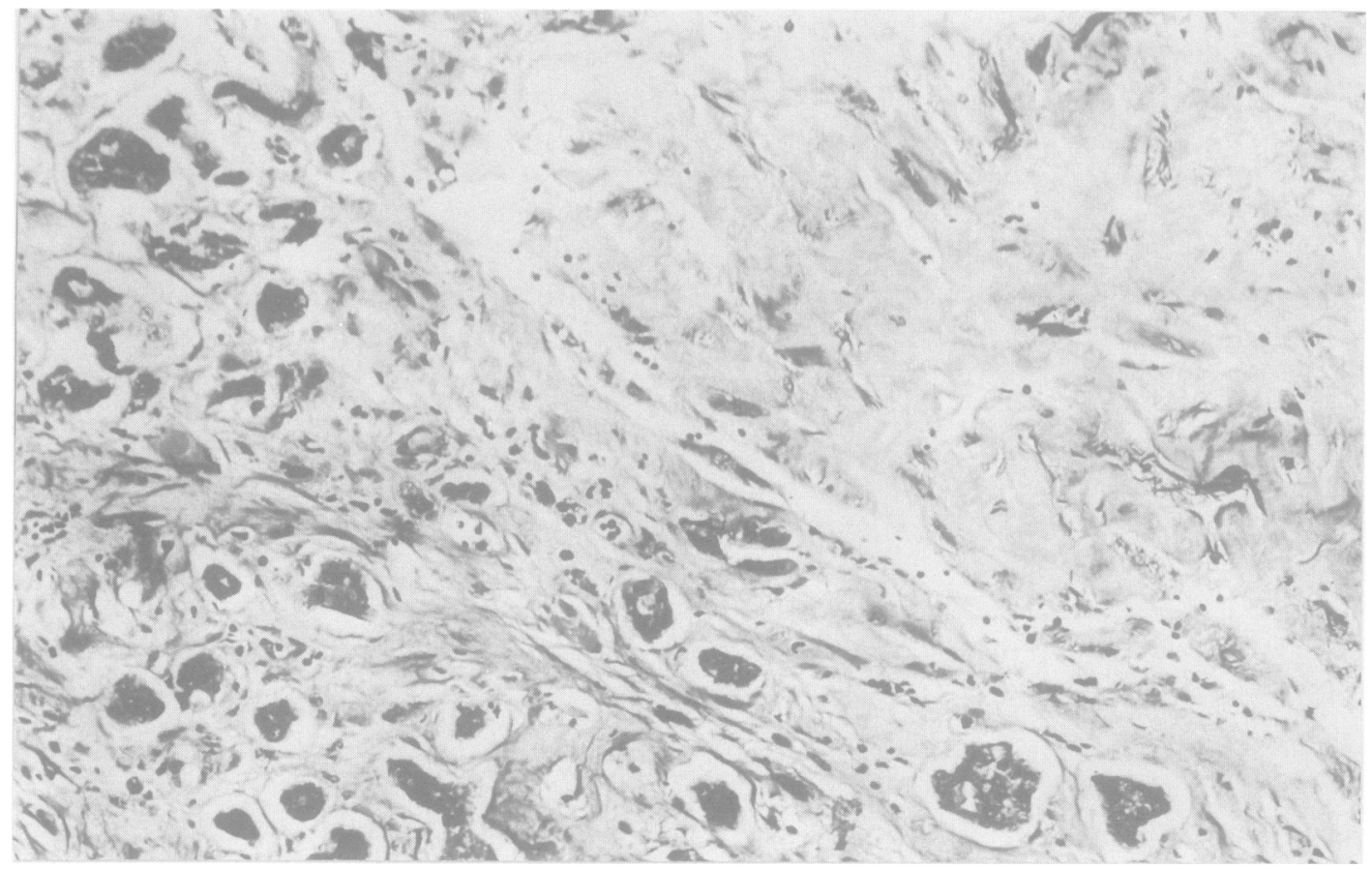

Fig 4 Section from the margin of a focal necrotic lesion showing myelin degeneration, vascular proliferation and a minor inflammatory cellular response (patient no. 5) (Kluver Stain, $\times 100)$.

an early transient decreased CSF flow.

For the development of DNL following MTX several mechanisms have been considered. ${ }^{152028-30}$ Apart from the direct toxic effect of MTX on glial and endothelial cells, the mental changes have been related to deficiencies of folic acid, serotonin and biogenic amines, caused by MTX. ${ }^{28} 29$

The neurotoxic effect of MTX is potentiated by cranial irradiation which induces endothelial damage resulting in an increased diffusion of MTX into the brain parenchyma. ${ }^{1728}$

The predilection for the periventricular white matter has been explained by impaired CSF flow from the ventricles with increased transependymal diffusion. ${ }^{16}$ Impaired flow over the convexities with increased absorption from the deep Virchow-Robin spaces may be a contributing factor. ${ }^{20}$ The absence of DNL after prophylactic treatment with IT MTX ${ }^{31}$ is in agreement with the significance of CSF flow disturbances due to the neoplastic meningitis. Postmortem examination in Patient 5 showing predominance of demyelination and necrosis in the direct vicinity of the lateral ventricles suggests that a pathologic transependymal diffusion of MTX may also occur at so called non-toxic ventricular CSF MTX levels.

A sensitisation or hypersensitivity response, as pro- posed in some other cases of MTX neurotoxicity ${ }^{32-34}$ can not be excluded as an underlying mechanism in causing the acute febrile reaction and DNL after low dose of MTX. However, disappearance of the fever during continued MTX administration is not in accordance with this hypothesis. ARA-C may cause DNL after high dose iv infusion ${ }^{35}$ but not after intrathecal administration ${ }^{36}$ and therefore did not contribute to the development of DNL in our patients.

The neuropathological findings show that apparent irradiation specific vascular changes can also be produced by IT MTX alone. Histologically, there was no striking difference between the two examined patients, although in Patient 1 the lesions can be interpreted as more acute. This patient had experienced a rapidly progressive course of the disease and only lived 1 month after the first signs of DNL. It may be speculated whether previous whole brain radiotherapy in this patient has played a role in the rapid development of these extensive necrotic lesions.

This study shows that DNL is not a rare complication of IT MTX therapy. The incidence is related to the cumulative dose of MTX and the duration of treatment as well as to whole brain radiotherapy. In addition, DNL may be induced by less than $50 \mathrm{mg}$ IT MTX in patients who have developed an acute reaction to IT MTX that consists of fever and mild 
encephalopathic symptoms. Because of this serious and debilitating late complication one has to be aware of this possible relation. As DNL occasionally is reversible it might be advisable to withhold MTX as soon as this acute encephalopathic reaction is noted, and replace it by ARA-C. The surprisingly high incidence of this serious complication makes the development of other chemotherapeutic agents or treatment modalities for meningeal carcinomatosis more urgent.

We thank Miss M MC van den Elzen and Mr OG H Lie for their secretarial assistance.

\section{References}

1 Bleyer WA, Poplack DG. Prophylaxis and treatment of leukemia in the central nervous system and other sanctuaries. Sem Oncol 1985;12:131-48.

2 Mackintosh FR, Colby TV, Podolsky WJ et al. Central nervous system involvement in non-Hodgkin's lymphoma. Cancer 1982;49:586-95.

3 Wasserstrom WR, Glass JP, Posner JB. Diagnosis and treatment of leptomeningeal metastasis from solid tumors. Cancer 1982;49:759-72.

4 Yap HY, Yap BS, Rasmussen S et al. Treatment for meningeal carcinomatosis in breast cancer. Cancer 1982;49:219-22.

5 Ongerboer de Visser BW, Somers R, Nooyen WH et al. Intraventricular methotrexate therapy of leptomeningeal metastasis from breast carcinoma. Neurology 1983;33:1565-72.

6 Duttera MJ, Bleyer WA, Pomeroy TC et al. Irradiation, methotrexate toxicity, and the treatment of meningeal leukemia. Lancet 1973;ii:703-7.

7 Gagliano RG, Costanzi JJ. Paraplegia following intrathecal methotrexate. Cancer 1976;37:1663-8.

8 Skullerud K, Halvorsen K. Encephalomyelopathy following intrathecal methotrexate treatment in a child with acute leukemia. Cancer 1978;42:1211-5.

9 Bleyer WA. Neurologic sequelae of methotrexate and ionizing radiation: A new classification. Cancer Treat Rep 1981;65: 89-98.

10 Naiman JL, Rupprecht LM, Tanyeri G, Philippidis P. Intrathecal methotrexate. Lancet 1970;i:571.

11 Geiser CF, Bishop Y, Jaffe N et al. Adverse effects of intrathecal methotrexate in children with acute leukemia in remission. Blood 1975;45:189-95.

12 Valerino DM. Methotrexate impurities., Lancet 1972;ii:1025-6.

13 Bleyer WA, Drake JC, Chabner BA. Neurotoxicity and elevated cerebrospinal fluid methotrexate concentration in meningeal leukemia. N Engl J Med 1973;289:770-3.

14 Kaplan RS, Wiernik PH. Neurotoxicity of antineoplastic drugs. Sem Oncol 1982;9:103-30.

15 Jellinger K. Pathologic effects of chemotherapy. In Walker MD (ed): Oncology of the Nervous System. Boston, Martinus Nijhoff 1983;285-340.

16 Shapiro WR, Chernik NL, Posner JB. Necrotising encephalopathy following intraventricular instillation of methotrexate. Arch Neurol 1973;28:96-102.

17 Price RA, Jamieson PA. The central nervous system in childhood leukemia II. Subacute leukoencephalopathy. Cancer 1975;35: 306-18.

18 Rubinstein LJ, Herman MM, Long TF et al. Disseminated leukoencephalopathy: a complication of treated central nervous system leukemia and lymphoma. Cancer 1975;35:291-305.

19 Pizzo PA, Bleyer WA, Poplack DG, Leventhal BG. Reversible dementia temporally associated with intraventricular therapy with methotrexate in a child with acute myelogenous leukemia. J Pediatr 1976;88:131-3.

20 Suzuki K, Takemura T, Okeda R, Hatakeyama S: Vascular changes of methotrexate-related disseminated necrotizing leukoencephalopathy. Acta Neuropathol 1984;65:145-9.

21 Bleyer WA. Clinical pharmacology of intrathecal methotrexate II. An improved dosage regimen derived from age-related pharmacokinetics. Cancer Treat Rep 1977;61:1419-25.

22 Duffner PK, Cohen ME, Brecher ML et al. CT abnormalities and altered methotrexate clearance in children with CNS leukemia. Neurology 1984;34:229-33.

23 Fusner JR, Poplack DG, Pizzo PA, Di Chiro G. Leukoencephalopathy following chemotherapy for rhabdomyosarcoma: reversibility of cerebral changes demonstrated by computed tomography. J Pediatr 1977;91:77-9.

24 Ochs JJ, Parvey LS, Whitaker JN et al. Serial cranial computedtomography scans in children with leukemia given two different forms of central nervous system therapy. J Clin Oncol 1983;1:793-8.

25 Gangji D, Reeman GH, Cohen SR et al. Leukoencephalopathy and elevated levels of myelin basic protein in the cerebrospinal fluid of patients with acute lymphoblastic leukemia. $N$ Engl J Med 1980;303:19-21.

26 Mahoney DH, Fernbach DJ, Glaze DG, Cohen SR. Elevated myelin basic protein in the cerebrospinal fluid of children with acute lymphoblastic leukemia. J Clin Oncol 1984;2:58-61.

27 Grossman SA, Trump DL, Chen DCP et al. Cerebrospinal fluid flow abnormalities in patients with neoplastic meningitis. $A m \mathbf{J}$ Med 1982;73:641-7.

28 Abelson HT. Methotrexate and central nervous system toxicity. Cancer Treat Rep 1978;62:1999-2001.

29 Allen JC, Rosen G, Mehta BM, Horten B. Leukoencephalopathy following high-dose IV methotrexate with leukovorin rescue. Cancer Treat Rep 1980;64:1261-73.

30 Glass JP, Lee YY, Bruner J, Fields WS. Treatment-related leukoencephalopathy. Medicine (Baltimore) 1986;65:154-62.

31 Ochs JJ, Berger P, Brecher ML et al. Computed tomography brain scans in children with acute lymphocytic leukemia receiving methotrexate alone as central nervous system prophylaxis. Cancer 1980;45:2274-8.

32 Back EH. Death after intrathecal methotrexate. Lancet 1969; ii: 1005 .

33 Young DF, Posner JB. Nervous system toxicity of the chemotherapeutic agents. In: Vinken P, Bruyn GW (eds). Handbook of Clinical Neurology. Amsterdam, Elsevier, North-Holland 1980;39:91-129.

34 Shapiro WR, Young DF. Neurological complications of antineoplastic therapy. Acta Neurol Scand 1984;70(suppl 100): 125-32.

35 Hwang TL, Yung WKA, Estey EH, Fields WS. Central nervous system toxicity with high-dose Ara-C. Neurology 1985;35: 1475-9.

36 Peylan-Ramu N, Poplack DG, Pizzo PA et al. Abnormal CTscans of the brain in asymptomatic children with acute lymphocytic leukemia after prophylactic treatment of the central nervous system with radiation and intrathecal chemotherapy. N Engl J Med 1978;298:815-8. 